\title{
CONSERVAÇÃO PÓS-COLHEITA DE FIGOS VERDES (Ficus carica L.) CV. ROXO DE VALINHOS TRATADOS COM HIPOCLORITO DE SÓDIO E ARMAZENADOSSOB REFRIGERAÇÃO EMATMOSFERA MODIFICADA PASSIVA
}

\author{
Post-harvest conservation of unripe figs (Ficus carica L.) cv. "roxo de valinhos" treated with \\ sodium hypochlorite and stored under refrigeration in passive modified atmosphere \\ Luciana Costa Limaㄹ, Mário Sérgio Carvalho Dias², Marcos Venícius de Castro ${ }^{3}$, Ramilo Nogueira Martins ${ }^{4}$, \\ Pedro Martins Ribeiro Júnior ${ }^{5}$, Enilson de Barros Silva ${ }^{6}$
}

\begin{abstract}
RESUMO
Os principais causadores de perdas da qualidade de figos são: colheita e embalagens inadequadas, falta de padronização do produto na classificação e péssimas condições de transporte e armazenamento. Com este trabalho objetivou-se avaliar o efeito da imersão em hipoclorito, tipo de embalagem e refrigeração na conservação pós-colheita de figos verdes, cv. Roxo de Valinhos, mediante as características físicas, físico-químicas e químicas, durante o armazenamento. Após seleção, os figos foram imersos ou não em solução de hipoclorito de sódio a $40 \mathrm{ppm}$ conforme os tratamentos, secos ao ar e embalados em filme de PVC de $50 \mathrm{~m}$ ou sacos plásticos. Após os tratamentos, os frutos foram submetidos a armazenamento refrigerado $\left(1^{\circ} \mathrm{C} \mathrm{e} 70 \%\right.$ de UR em BOD), por um período de 35 dias, sendo avaliados a cada 7 dias. O uso da embalagem reduziu drasticamente a perda de massa dos figos. Frutos não embalados apresentaram-se mais ácidos e com menores teores de açúcares. Com o uso da embalagem, os figos podem ser comercializados até os 35 dias de armazenamento desde que armazenados a $1^{\circ} \mathrm{C}$ e $70 \%$ de UR em BOD. Já os figos não embalados, estes podem ser comercializados somente até os 2 dias de armazenamento sob refrigeração.
\end{abstract}

Termos para indexação: qualidade, armazenamento, embalagem e Ficus carica.

\begin{abstract}
The chief causes of quality loss in figs are inadequate harvest and packaging, lack of standardization of the product in the classification and very bad transportation and storage conditions. This work aimed to evaluate the effects of soaking in hypochlorite, and the type of packaging and refrigeration on the post-harvest conservation of unripe figs cv. "Roxo de Valinhos", through physicochemical analyses, during storage. After selection, the figs were soaked, or not, in a 40ppm sodium hypochlorite solution, air-dried and wrapped in 50 $\mu$ PVC film or plastic bags. After the treatments, the fruits were submitted to refrigerated storage $\left(1{ }^{\circ} \mathrm{C}\right.$ and $70 \%$ of RH) for a 35-day period, being evaluated every 7 days. Use of the packaging drastically reduced the loss of the figs' mass. Nonwrapped fruits were more acidic and had a lower sugar content. By the use of the packaging, the figs may be commercialized until 35 days of storage so long as are stored at $1^{\circ} \mathrm{C}$ and $70 \%$ of $\mathrm{RH}$. The non-wrapped figs may be commercialized only until 2 days of storage under refrigeration.
\end{abstract}

Index tems: quality, storage, package and Ficus carica.

(Recebido para publicação em 30 de abril de 2004 e aprovado em 31 de março de 2005)

\section{INTRODUÇÃO}

A figueira (Ficus carica L.) é uma das plantas mais antigas cultivadas no mundo. O Brasil é o segundo maior exportador de figos com 800 toneladas, sendo superado apenas pela Turquia, que exporta cerca de 40.000 toneladas anuais. Apesar de uma quantidade modesta, ainda assim, o Brasil consegue exportar figo para a Europa, na entressafra da Turquia. Minas Gerais apresenta uma produção em torno de 1.200 toneladas e vem destacando-se como o terceiro maior produtor brasileiro de figos, ficando atrás somente de São Paulo e Rio Grande do Sul (ALMEIDA \& MARTIN, 1997).

No caso das frutas temperadas e, em particular, do figo, a alta perecibilidade resulta na necessidade de transporte rápido para os centros de consumo. Os principais causadores de perdas da qualidade de figos são: colheita e embalagem inadequadas, falta de padronização do produto na classificação e péssimas condições de transporte e armazenamento (PENTEADO, 1998).

\footnotetext{
${ }^{1}$ Engenheira Agrônoma, M.Sc., aluna de Doutorado em Horticultura na Universidade Estadual Paulista Júlio de Mesquita Filho - Botucatu, SP limalc@fca.unesp.br

2 Engenheiro Agrônomo, D.Sc., pesquisador do Centro Tecnológico do Norte de Minas - Nova Porteirinha, MG - diasmsc@nortecnet.com.br

${ }^{3}$ Biólogo, M.Sc., Professor Adjunto da Univale - Governador Valadares, MG - marcoscastro@hotmail.com

${ }^{4}$ Engenheiro Agrônomo, aluno de Mestrado em Ciência dos Alimentos na Universidade Federal de Lavras/UFLA - Caixa Postal 3037 - $37.200-000$ Lavras, MG - martinsnr@hotmail.com

${ }^{5}$ Engenheiro Agrônomo, aluno de Mestrado em Fitopatologia na Universidade Federal de Lavras/UFLA - pedromartinsjr@bol.com.br

${ }^{6}$ Engenheiro Agrônomo, D.Sc., Professor Adjunto da Universidade de Diamantina - Diamantina, MG - benilson@hotmail.com
} 
A refrigeração para o figo é recomendada por diversos autores, entre os quais Westwood (1982). Para este, o ideal são as baixas temperaturas, em torno de $0^{\circ} \mathrm{C}$, nas câmaras frigoríficas, que mantém a boa conservação de figos frescos. Mas para Spagnol et al. (1994), embora a refrigeração se apresente como uma prática eficiente na redução das perdas pós-colheita, a suplementação com a atmosfera modificada ou atmosfera controlada, poderá trazer melhores benefícios, quando usada adequadamente. Desta forma, o desenvolvimento de técnicas e meios de conservação podem reduzir as perdas no transporte e manter os frutos com boa qualidade para consumo por mais tempo. Diante destas observações, objetivou-se caracterizar o efeito do hipoclorito e embalagem na conservação pós-colheita de figos verdes da cv. Roxo-deValinhos, armazenados sob refrigeração $\left(1^{\circ} \mathrm{Ce} 70 \%\right.$ de UR em BOD), mediante as modificações nas características físicas, físico-químicas e químicas por um período de 35 dias.

\section{MATERIALEMÉTODOS}

Figos provenientes da Fazenda Experimental de Mocambinho - MG que pertence ao Centro Tecnológico do Norte de Minas da Empresa de Pesquisa Agropecuária de Minas Gerais (EPAMIG), foram colhidos em estádio verde de maturação na safra de 2000. Realizou-se seleção de acordo com a uniformidade de cor, tamanho e ausência de injúrias mecânicas e fisiológicas. Os frutos foram imersos ou não em solução de hipoclorito de sódio a 40 ppm e após secagem ao ar por 1 hora, foram acondicionados em bandejas plásticas recobertas com polietileno (espessura de $50 \mathrm{~m}$ ) ou sacos plásticos 20 x $30 \mathrm{~cm}$ de alta densidade. Os frutos foram submetidos a armazenamento refrigerado $\left(1^{\circ} \mathrm{C}\right.$ e $70 \%$ de UR em BOD), por um período de 35 dias e avaliados quanto às características intrínsecas de qualidade a cada 7 dias.

$\mathrm{O}$ delineamento experimental foi o inteiramente casualizado em esquema fatorial, com 5 tratamentos e 6 tempos de armazenamento: ( $0,7,14,21,28$ e 35 dias), 4 repetições e 20 frutos por unidade experimental. Os tratamentos avaliados foram: Controle - frutos não embalados e não tratados com hipoclorito de sódio a 40 ppm (C); Frutos acondicionados em bandejas de isopor e recobertos com PVC (BS); Frutos imersos em hipoclorito de sódio a 40 ppm, acondicionados em bandejas de isopor e recobertos com PVC (BC); Frutos acondicionados em sacos plásticos (SS); Frutos imersos em hipoclorito de sódio a 40 ppm e acondicionados em sacos plásticos (SC).
Procedeu-se à caracterização física dos frutos quanto a perda de massa (g), por pesagem individual dos frutos e firmeza da polpa $(\mathrm{N})$, em penetrômetro de mão marca TR, modelo 327 , determinada pela força de penetração necessária para que a agulha de $2,5 \mathrm{~cm}$ de 0,8 $\mathrm{cm}$ de diâmetro penetre no fruto sendo as medidas tomadas na região central dos frutos com casca e transformadas em Newton. As análises físico-químicas e químicas foram realizadas após homogeneização da polpa conjuntamente com a casca e constaram das seguintes variáveis: $\mathrm{pH}$, por potenciometria (AOAC, 1990); sólidos solúveis totais, obtido por refratometria, expressando-se os resultados em ${ }^{\circ}$ Brix (AOAC, 1990); acidez total titulável, por titulação com hidróxido de sódio $0,1 \mathrm{~N}$ e fenolftaleína como indicador expressando-se os resultados em Mol L $\mathrm{L}^{-1}$ (IAL, 1985) e açucares solúveis totais (\% de glicose, frutose e sacarose) dosados pela técnica de Somoghy adaptada por Nelson (1944).

Os dados foram submetidos à análise de variância e posterior teste de médias, segundo Gomes (1985).

\section{RESULTADOS E DISCUSSÃO}

A perda de massa dos figos foi influenciada pela embalagem no decorrer do tempo de armazenamento $(\mathrm{P}<0,01)$. Com base nos resultados apresentados na Tabela 1, verifica-se que os frutos não embalados (controle) foram os que apresentaram maior perda de massa ao longo do armazenamento, com perda de $79 \%$ do seu peso inicial, seguido pelos frutos embalados em PVC com $17 \%$ e por último os embalados em sacos plásticos com perda de $4 \%$.

Os frutos embalados em saco plástico apresentaram a menor perda de massa, o que pode estar relacionada a maior espessura da embalagem em comparação ao PVC. Desta forma, ocorre menor perda de água dos frutos e conseqüentemente menor redução da massa. Com base nos resultados obtidos, observa-se a necessidade de manter os frutos embalados, mesmo quando estes são armazenados em baixas temperaturas, para evitar a perda de massa dos frutos. A umidade relativa também deve ser observada, pois quanto mais elevada ela for, menor será a perda de massa dos frutos.

Kluge \& Jorge (1992), demonstraram que o uso de embalagem, principalmente de filme de polietileno, reduz drasticamente as perdas de massa de frutos e hortaliças, tanto no armazenamento, quanto na comercialização. Outros trabalhos de pesquisa também têm comprovado a eficácia do uso da embalagem de 
polietileno, em condições de baixas temperaturas $\left(0 \mathrm{a} 5^{\circ} \mathrm{C}\right)$, na manutenção da qualidade do figo (MATHOOKO et al., 1993; VIDIGAL et al., 1981).
Com relação à firmeza, diferenças significativas $(\mathrm{P}<0,01)$, só foram detectadas aos 35 dias de armazenamento conforme mostra a Tabela 2 .

TABELA 1 - Valores médios de perda de massa (g), de figos verdes cv. Roxo de Valinhos, armazenados sob refrigeração em AM $\left(1{ }^{\circ} \mathrm{C}\right.$ e $70 \%$ de UR em BOD), durante 35 dias.

\begin{tabular}{ccccccc}
\hline Tratamentos & \multicolumn{7}{c}{ Tempo de Armazenamento (dias) } \\
\cline { 2 - 7 } & $\mathbf{0}$ & $\mathbf{7}$ & $\mathbf{1 4}$ & $\mathbf{2 1}$ & $\mathbf{2 8}$ & $\mathbf{3 5}$ \\
\hline $\mathrm{C}$ & $10,90 \mathrm{~b}$ & $8,80 \mathrm{c}$ & $6,30 \mathrm{c}$ & $4,00 \mathrm{c}$ & $2,90 \mathrm{c}$ & $2,30 \mathrm{c}$ \\
BS & $13,65 \mathrm{a}$ & $13,55 \mathrm{a}$ & $13,35 \mathrm{a}$ & $13,00 \mathrm{a}$ & $12,55 \mathrm{a}$ & $11,90 \mathrm{a}$ \\
BC & $12,65 \mathrm{a}$ & $12,40 \mathrm{~b}$ & $11,95 \mathrm{~b}$ & $11,40 \mathrm{~b}$ & $10,90 \mathrm{~b}$ & $10,00 \mathrm{~b}$ \\
SS & $12,95 \mathrm{a}$ & $12,80 \mathrm{ab}$ & $12,80 \mathrm{ab}$ & $12,75 \mathrm{a}$ & $12,65 \mathrm{a}$ & $12,45 \mathrm{a}$ \\
SC & $13,00 \mathrm{a}$ & $12,95 \mathrm{ab}$ & $12,90 \mathrm{ab}$ & $12,75 \mathrm{a}$ & $12,70 \mathrm{a}$ & $12,50 \mathrm{a}$ \\
\hline
\end{tabular}

Médias seguidas de mesma letra, na vertical, não diferem entre si ao nível de $1 \%$ de significância pelo Teste de Tukey. $\mathbf{C}=$ frutos não embalados e não tratados com hipoclorito a $40 \mathrm{ppm}, \mathbf{B S}=$ frutos acondicionados em bandejas de isopor e recobertos com $\mathrm{PVC}, \mathbf{B C}=$ frutos imersos em hipoclorito a $40 \mathrm{ppm}$, acondicionados em bandejas de isopor e recobertos com $\mathrm{PVC}, \mathbf{S S}=$ frutos acondicionados em sacos plásticos, $\mathbf{S C}=$ frutos imersos em hipoclorito a 40ppm e acondicionados em sacos plásticos.

TABELA 2 - Valores médios de firmeza (N), de figos verdes cv. Roxo de Valinhos, armazenados sob refrigeração em AM $\left(1{ }^{\circ} \mathrm{C}\right.$ e $70 \%$ de UR em BOD), durante 35 dias.

\begin{tabular}{ccccccc}
\hline Tratamentos & \multicolumn{7}{c}{ Tempo de Armazenamento (dias) } \\
\cline { 2 - 7 } & $\mathbf{0}$ & $\mathbf{7}$ & $\mathbf{1 4}$ & $\mathbf{2 1}$ & $\mathbf{2 8}$ & $\mathbf{3 5}$ \\
\hline C & $10,58 \mathrm{a}$ & --- & --- & --- & --- & -- \\
BS & $10,58 \mathrm{a}$ & $8,20 \mathrm{a}$ & $8,32 \mathrm{a}$ & $8,03 \mathrm{a}$ & $8,00 \mathrm{a}$ & $7,04 \mathrm{a}$ \\
BC & $10,58 \mathrm{a}$ & $8,22 \mathrm{a}$ & $8,55 \mathrm{a}$ & $7,47 \mathrm{a}$ & $7,50 \mathrm{a}$ & $7,71 \mathrm{a}$ \\
SS & $10,58 \mathrm{a}$ & $8,51 \mathrm{a}$ & $8,63 \mathrm{a}$ & $7,78 \mathrm{a}$ & $8,17 \mathrm{a}$ & $5,91 \mathrm{ab}$ \\
SC & $10,58 \mathrm{a}$ & $8,51 \mathrm{a}$ & $7,91 \mathrm{a}$ & $6,76 \mathrm{a}$ & $7,62 \mathrm{a}$ & $4,76 \mathrm{~b}$
\end{tabular}

Médias seguidas de mesma letra, na vertical, não diferem entre si ao nível de $1 \%$ de significância pelo Teste de Tukey. $\mathbf{C}=$ frutos não embalados e não tratados com hipoclorito a $40 \mathrm{ppm}, \mathbf{B S}=$ frutos acondicionados em bandejas de isopor e recobertos com PVC, $\mathbf{B C}=$ frutos imersos em hipoclorito a $40 \mathrm{ppm}$, acondicionados em bandejas de isopor e recobertos com $\mathrm{PVC}, \mathbf{S S}=$ frutos acondicionados em sacos plásticos, $\mathbf{S C}=$ frutos imersos em hipoclorito a 40 ppm e acondicionados em sacos plásticos.

Ciênc. agrotec., Lavras, v. 29, n. 4, p. 810-816, jul./ago., 2005 
Os frutos embalados em PVC perderam mais massa que os embalados em saco plástico, no entanto, estes apresentaram valores elevados de firmeza aos 35 dias de armazenamento. Tais resultados podem ter sido mascarados pela perda de massa dos frutos que ocasiona enrugamento dos tecidos tornando a polpa elástica e dificultando a entrada do penetrômetro. Segundo Vidigal et al. (1981), o figo, ao amadurecer, torna-se murcho ou "emborrachado", afetando dessa forma a correta determinação da firmeza pelo penetrômetro. Os frutos do presente trabalho não amadureceram, mas tornaram-se murchos devido à excessiva perda de massa mascarando dessa forma os valores de firmeza.

Para frutos não embalados (controle), a firmeza não pôde ser medida após a colheita devido ao enrugamento excessivo dos frutos, pois estes perderam água rapidamente após a colheita. Segundo Mathooko et al. (1993), esse comportamento é decorrente da ação de enzimas que atuam na hidrólise do amido, da transformação dos constituintes celulósicos da parede celular, bem como da conversão da protopectina em pectina solúvel e excessiva perda de água dos frutos. Nos demais tratamentos, estes processos foram retardados pela embalagem e refrigeração.

Quanto ao $\mathrm{pH}$, as diferenças só foram significativas $(\mathrm{P}<0,01)$ aos 21 e 35 dias de armazenamento, mas as variações observadas são consideradas pequenas (Tabela 3 ).

Segundo Chitarra \& Chitarra (1990), a capacidade tampão de alguns sucos resulta em apenas pequenas variações no $\mathrm{pH}$. $\mathrm{O} \mathrm{pH}$ médio dos frutos ficou em torno de 6,00, bem próximo ao observado por Penteado (1998) que encontrou valor médio de 5,00.

Com relação aos sólidos solúveis totais (SST), observa-se com o tempo uma redução mais acentuada dos 14 aos 21 dias de armazenamento, igualando-se os teores ao final do armazenamento (Tabela 4).

A variável acidez total titulável (ATT) foi influenciada pelo tipo de embalagem e pelo tempo de armazenamento $(\mathrm{P}<0,01)$. Aos 7 e 14 dias, os frutos controle apresentaram teores elevados de acidez (Tabela 5). Resultado semelhante foi observado por Bleinroth (1989), que cita que devido às perdas transpiracionais o fruto verde "murcha", permanece com a polpa esbranquiçada, firme, ácida e sem sabor.

Aos 21 dias de armazenamento, os frutos embalados em sacos plásticos e imersos em hipoclorito de sódio a $40 \mathrm{ppm}$, apresentaram valor bem maior de acidez que os demais $\left(8,29 \mathrm{Mol} \mathrm{L}^{-1}\right)$. Possivelmente isto ocorreu devido à fermentação dos frutos armazenados sob esta condição em decorrência do acúmulo de água na embalagem.

O teor médio de acidez dos frutos do presente trabalho foi de 3,75 Mol L-1 (Tabela 5), valor este condizente ao encontrado por Penteado (1998) quando trabalhou com figos verdes da cv. Roxo de Valinhos no Estado de São Paulo.

TABELA 3 - Valores médios de pH, de figos verdes cv. Roxo de Valinhos, armazenados sob refrigeração e AM $\left(1^{\circ} \mathrm{C}\right.$ e $70 \%$ de UR em BOD $)$, durante 35 dias.

\begin{tabular}{ccccccc}
\hline Tratamentos & \multicolumn{5}{c}{ Tempo de Armazenamento (dias) } \\
\cline { 2 - 7 } & $\mathbf{0}$ & $\mathbf{7}$ & $\mathbf{1 4}$ & $\mathbf{2 1}$ & $\mathbf{2 8}$ & $\mathbf{3 5}$ \\
\hline C & $6,17 \mathrm{a}$ & $5,46 \mathrm{a}$ & $5,91 \mathrm{a}$ & $6,33 \mathrm{a}$ & $6,26 \mathrm{a}$ & $6,08 \mathrm{ab}$ \\
BS & $6,17 \mathrm{a}$ & $6,32 \mathrm{a}$ & $6,12 \mathrm{a}$ & $6,21 \mathrm{a}$ & $6,03 \mathrm{a}$ & $6,31 \mathrm{a}$ \\
BC & $6,17 \mathrm{a}$ & $6,20 \mathrm{a}$ & $5,88 \mathrm{a}$ & $6,04 \mathrm{ab}$ & $6,28 \mathrm{a}$ & $5,99 \mathrm{ab}$ \\
SC & $6,17 \mathrm{a}$ & $5,91 \mathrm{a}$ & $6,27 \mathrm{a}$ & $5,79 \mathrm{ab}$ & $5,77 \mathrm{a}$ & $5,24 \mathrm{~b}$ \\
SS & $6,17 \mathrm{a}$ & $5,95 \mathrm{a}$ & $5,64 \mathrm{a}$ & $5,31 \mathrm{~b}$ & $5,99 \mathrm{a}$ & $5,67 \mathrm{ab}$
\end{tabular}

Médias seguidas de mesma letra, na vertical, não diferem entre si ao nível de 1\% de significância pelo Teste de Tukey. $\mathbf{C}=$ frutos não embalados e não tratados com hipoclorito a $40 \mathrm{ppm}, \mathbf{B S}=$ frutos acondicionados em bandejas de isopor e recobertos com $\mathrm{PVC}, \mathbf{B C}=$ frutos imersos em hipoclorito a $40 \mathrm{ppm}$, acondicionados em bandejas de isopor e recobertos com $\mathbf{P V C}, \mathbf{S S}=$ frutos acondicionados em sacos plásticos, $\mathbf{S C}=$ frutos imersos em hipoclorito a 40 ppm e acondicionados em sacos plásticos. 
TABELA 4 - Valores médios de sólidos solúveis totais ( ${ }^{\circ}$ Brix), de figos verdes cv. Roxo de Valinhos, armazenados sob refrigeração e AM $\left(1{ }^{\circ} \mathrm{C}\right.$ e $70 \%$ de UR em BOD), durante 35 dias.

\begin{tabular}{ccccccc}
\hline Tratamentos & \multicolumn{7}{c}{ Tempo de Armazenamento (dias) } \\
\cline { 2 - 7 } & $\mathbf{0}$ & $\mathbf{7}$ & $\mathbf{1 4}$ & $\mathbf{2 1}$ & $\mathbf{2 8}$ & $\mathbf{3 5}$ \\
\hline C & $5,73 \mathrm{a}$ & $6,30 \mathrm{a}$ & $6,00 \mathrm{a}$ & $3,30 \mathrm{~b}$ & $2,70 \mathrm{~b}$ & $3,00 \mathrm{a}$ \\
BS & $5,73 \mathrm{a}$ & $5,93 \mathrm{a}$ & $6,15 \mathrm{a}$ & $3,68 \mathrm{ab}$ & $3,23 \mathrm{ab}$ & $3,38 \mathrm{a}$ \\
BC & $5,73 \mathrm{a}$ & $5,55 \mathrm{a}$ & $6,08 \mathrm{a}$ & $3,90 \mathrm{ab}$ & $3,08 \mathrm{ab}$ & $3,75 \mathrm{a}$ \\
SS & $5,73 \mathrm{a}$ & $6,00 \mathrm{a}$ & $5,63 \mathrm{a}$ & $3,30 \mathrm{~b}$ & $3,60 \mathrm{a}$ & $3,68 \mathrm{a}$ \\
SC & $5,73 \mathrm{a}$ & $5,85 \mathrm{a}$ & $5,55 \mathrm{a}$ & $4,28 \mathrm{a}$ & $3,90 \mathrm{a}$ & $3,00 \mathrm{a}$ \\
\hline
\end{tabular}

Médias seguidas de mesma letra, na vertical, não diferem entre si ao nível de 1\% de significância pelo Teste de Tukey. $\mathbf{C}=$ frutos não embalados e não tratados com hipoclorito a $40 \mathrm{ppm}, \mathbf{B S}=$ frutos acondicionados em bandejas de isopor e recobertos com PVC, $\mathbf{B C}=$ frutos imersos em hipoclorito a $40 \mathrm{ppm}$, acondicionados em bandejas de isopor e recobertos com $\mathbf{P V C}, \mathbf{S S}=$ frutos acondicionados em sacos plásticos, $\mathbf{S C}=$ frutos imersos em hipoclorito a 40 ppm e acondicionados em sacos plásticos.

TABELA 5 - Valores médios de acidez total titulável $\left(\mathrm{Mol} \mathrm{L}^{-1}\right)$, de figos verdes cv. Roxo de Valinhos, armazenados sob refrigeração e AM $\left(1^{\circ} \mathrm{C}\right.$ e $70 \%$ de UR em BOD), durante 35 dias.

\begin{tabular}{ccccccc}
\hline Tratamentos & \multicolumn{5}{c}{ Tempo de Armazenamento (dias) } \\
\cline { 2 - 7 } & $\mathbf{0}$ & $\mathbf{7}$ & $\mathbf{1 4}$ & $\mathbf{2 1}$ & $\mathbf{2 8}$ & $\mathbf{3 5}$ \\
\hline C & $2,02 \mathrm{a}$ & $6,02 \mathrm{a}$ & $6,89 \mathrm{a}$ & $6,63 \mathrm{~b}$ & $1,17 \mathrm{~b}$ & $1,00 \mathrm{c}$ \\
BS & $2,02 \mathrm{a}$ & $3,48 \mathrm{~b}$ & $4,28 \mathrm{~b}$ & $3,67 \mathrm{c}$ & $2,38 \mathrm{ab}$ & $3,33 \mathrm{~b}$ \\
BC & $2,02 \mathrm{a}$ & $3,67 \mathrm{~b}$ & $4,65 \mathrm{~b}$ & $4,49 \mathrm{c}$ & $2,06 \mathrm{ab}$ & $3,79 \mathrm{~b}$ \\
SS & $2,02 \mathrm{a}$ & $4,70 \mathrm{ab}$ & $3,81 \mathrm{~b}$ & $4,32 \mathrm{c}$ & $2,29 \mathrm{ab}$ & $5,43 \mathrm{a}$ \\
SC & $2,02 \mathrm{a}$ & $3,92 \mathrm{~b}$ & $5,03 \mathrm{~b}$ & $8,29 \mathrm{a}$ & $2,70 \mathrm{a}$ & $4,29 \mathrm{ab}$ \\
\hline
\end{tabular}

Médias seguidas de mesma letra, na vertical, não diferem entre si ao nível de $1 \%$ de significância pelo Teste de Tukey. $\mathbf{C}=$ frutos não embalados e não tratados com hipoclorito a $40 \mathrm{ppm}, \mathbf{B S}=$ frutos acondicionados em bandejas de isopor e recobertos com $\mathrm{PVC}, \mathbf{B C}=$ frutos imersos em hipoclorito a $40 \mathrm{ppm}$, acondicionados em bandejas de isopor e recobertos com $\mathbf{P V C}, \mathbf{S S}=$ frutos acondicionados em sacos plásticos, $\mathbf{S C}=$ frutos imersos em hipoclorito a $40 \mathrm{ppm}$ e acondicionados em sacos plásticos.

Quanto ao teor de açúcares solúveis totais (AST), diferenças foram significativas $(\mathrm{P}<0,01)$ a partir dos 7 dias de armazenamento, quando frutos controle apresentaram maior teor (Tabela 6). Ao final do armazenamento, os frutos não embalados (controle) continuaram apresentando o maior teor e os demais tratamentos foram iguais entre si.

Com a desidratação dos frutos, ocorre uma concentração dos açúcares, portanto nota-se que frutos não embalados (controle) foram os que apresentaram maior perda de massa ao longo do armazenamento (79\%) que conseqüentemente resultou nos maiores teores de açúcares.

Normalmente, o teor de AST aumenta com o amadurecimento dos frutos mediante processos de biossíntese ou pela degradação de polissacarídeos (CHITARRA \& CHITARRA, 1990). Whiting (1970), também confirma que o teor de açúcares aumenta gradativamente durante os primeiros estádios do desenvolvimento do fruto 
TABELA 6 - Valores médios de açúcares solúveis totais (\% de glicose, frutose e sacarose), de figos verdes cv. Roxo de Valinhos, armazenados sob refrigeração e AM $\left(1^{\circ} \mathrm{C}\right.$ e $70 \%$ de UR em BOD), durante 35 dias.

\begin{tabular}{ccccccc}
\hline Tratamentos & \multicolumn{7}{c}{ Tempo de Armazenamento (dias) } \\
\cline { 2 - 7 } & $\mathbf{0}$ & $\mathbf{7}$ & $\mathbf{1 4}$ & $\mathbf{2 1}$ & $\mathbf{2 8}$ & $\mathbf{3 5}$ \\
\hline $\mathrm{C}$ & $2,94 \mathrm{a}$ & $3,90 \mathrm{a}$ & $5,10 \mathrm{a}$ & $2,98 \mathrm{a}$ & $3,17 \mathrm{~b}$ & $3,20 \mathrm{a}$ \\
BS & $2,94 \mathrm{a}$ & $2,76 \mathrm{~b}$ & $2,80 \mathrm{~b}$ & $2,08 \mathrm{bc}$ & $2,90 \mathrm{a}$ & $2,24 \mathrm{~b}$ \\
BC & $2,94 \mathrm{a}$ & $3,19 \mathrm{ab}$ & $2,92 \mathrm{~b}$ & $2,77 \mathrm{ab}$ & $1,78 \mathrm{c}$ & $2,07 \mathrm{~b}$ \\
SS & $2,94 \mathrm{a}$ & $3,49 \mathrm{ab}$ & $2,78 \mathrm{~b}$ & $1,97 \mathrm{c}$ & $2,51 \mathrm{bc}$ & $1,95 \mathrm{~b}$ \\
SC & $2,94 \mathrm{a}$ & $3,20 \mathrm{ab}$ & $2,76 \mathrm{~b}$ & $2,19 \mathrm{bc}$ & $1,83 \mathrm{c}$ & $1,88 \mathrm{~b}$
\end{tabular}

Médias seguidas de mesma letra, na vertical, não diferem entre si ao nível de $1 \%$ de significância pelo Teste de Tukey. $\mathbf{C}=$ frutos não embalados e não tratados com hipoclorito a $40 \mathrm{ppm}, \mathbf{B S}=$ frutos acondicionados em bandejas de isopor e recobertos com $\mathrm{PVC}, \mathbf{B C}=$ frutos imersos em hipoclorito a $40 \mathrm{ppm}$, acondicionados em bandejas de isopor e recobertos com PVC, $\mathbf{S S}=$ frutos acondicionados em sacos plásticos, $\mathbf{S C}=$ frutos imersos em hipoclorito a $40 \mathrm{ppm}$ e acondicionados em sacos plásticos.

e rapidamente nos últimos estádios de maturação, dependendo da cultivar. Dessa forma nota-se que o uso da embalagem no presente trabalho foi eficaz em retardar o aumento dos AST pela redução dos processos metabólicos dos frutos.

Outro fator interessante observado neste trabalho foi a não detecção de infecção nos frutos, o que descarta a utilização do hipoclorito de sódio a $40 \mathrm{ppm}$ na conservação dos figos armazenados sob as condições do presente trabalho. A baixa temperatura pode explicar melhor este comportamento, pois, segundo Eskin et al. (1971), as baixas temperaturas diminuem a taxa de crescimento de microorganismos que podem atacar as frutas e hortaliças. Tratamentos fungicidas efetuados na lavoura também podem contribuir para tal resultado.

\section{CONCLUSÕES}

O uso da embalagem de PVC e sacos plásticos reduziu drasticamente a perda de massa de figos verdes produzidos no Norte de Minas Gerais. No entanto, estes não devem ser comercializados em sacos plásticos, pois ocorre condensação de água dentro da embalagem e a mesma é de difícil manuseio no transporte e comercialização.

A não detecção de infecção nos frutos descarta a utilização do hipoclorito de sódio a 40 ppm na conservação dos figos armazenados sob as condições do presente trabalho.

Com o uso da embalagem, os figos podem ser comercializados até os 35 dias de armazenamento a $1^{\circ} \mathrm{Ce}$
$70 \%$ de UR em BOD. Já os figos não embalados, estes podem ser comercializados somente até os 2 dias de armazenamento sob refrigeração.

\section{REFERÊNCIASBIBLIOGRÁFICAS}

ALMEIDA, M. E. M.; MARTIN, Z. J. de. A industrialização do figo (Ficus carica, L.). Informe Agropecuário, Belo Horizonte, v. 18, n. 188, p. 14-21, 1997.

ASSOCIATION OFOFFICIALANALITICALCHEMISTS. Official methods of analisys of the Association of Official Analitical Chemists. 15. ed. Washington, 1990. 2 v.

BLEINROTH, E. W. Manuseio e tratamento de pós-colheita da manga. In: SIMPÓSIO BRASILEIRO SOBRE MANGICULTURA, 2., 1989, Jaboticabal. Anais... Jaboticabal: UNESP/FCAVJ, 1989. p. 171-184.

CHITARRA, M. I. F.; CHITARRA, A. B. Pós-colheita de frutos e hortaliças: fisiologia e manuseio. Lavras: ESAL/ FAEPE, $1990.320 \mathrm{p}$.

ESKIN, N. A. M.; HENDERSON, H. M.; TOWNSEND, R. J. Biochemistry of foods. New York: Academic, 1971.240 p.

GOMES, F. P. Curso de estatística experimental. 11. ed. São Paulo: Nobel, 1985. 466 p. 
INSTITUTO ADOLFO LUTZ. Normas analíticas do Instituto Adolfo Lutz: métodos químicos e físicos para análise de alimentos. 3. ed. São Paulo, 1985. v. 1, 371 p.

KLUGE, R. A.; JORGE, R. Efeito da embalagem de polietileno na frigoconservação de ameixas 'Amarelinhas'. Revista Brasileira de Fruticultura, Cruz das Almas, v. 231, n. 3, p. 21-25, 1992.

MATHOOKO, F. M.; SOTOKAMA, T.; KUBO, Y.; INABA, A.; NAKAMURA, R. Retention of freshness in fig fruit by $\mathrm{CO} 2$, enriched atmosphere. Japan Society Hortculture Science, Okayama, v. 62, n. 3, p. 661-667, 1993.

NELSON, N. A. A photometric adaptation of Somoghy method for the determination of glucose. Journal of Biological Chemistry, Baltimore, v. 15, n. 1, p. 375-380, 1944.

PENTEADO, S. R. Uso de atmosfera modificada e embalagens ativas, na conservação do figo 'Roxo de
Valinhos' (Ficus carica, L.). 1998. 100 f. Tese (Doutorado em Agronomia) - Escola Superior de Agricultura "Luiz de Queiroz”, Piracicaba, 1998.

SPAGNOL, A. W.; ROCHA, J. L. V.; PARK, K. J. Pré resfriamento de frutas e hortaliças. Informativo Agropecuário, Belo Horizonte, v. 17, p. 5-9, 1994.

VIDIGAL et al. Conservação do figo 'Roxo de Valinhos' em refrigeração. In: GONGRESSO BRASILEIRO DE FRUTICULTURA, 6., 1981, Recife. Anais... Recife: SBF, 1981.n. 3, p. 732-737.

WESTWOOD, N. H. Fruticultura de zonas templadas. Madrid Castello: Mundi, 1982. 461 p.

WHITING, G. Sugars. In: The biocheministry of fruit and their products. London: Academic, 1970. v. 1, p. $1-31$. 